\section{Endogenes Thrombinbildungspotenzial}

\section{T. Stief}

Institut für Laboratoriumsmedizin und Pathobiochemie, Krankenhaus der Philipps-Universität, Marburg, Deutschland

\section{Synonym(e) ETP}

Englischer Begriff endogenous thrombin potential (ETP)

Definition ETP ist die Menge an Thrombin, die gebildet werden kann, nachdem die Gerinnung durch Zugabe von - Tissue Factor (TF) und Phospholipiden gestartet wird. Der Test basiert auf der Vorstellung, dass die integrierte Gesamtmenge an Thrombin, die gebildet werden kann, letztlich die Balance zwischen den prokoagulatorischen und antikoagulatorischen Substanzen repräsentieren könnte. Eine einzige Messung der F2a-Aktivität im ansteigenden Bereich der Thrombin-Generierungs-Kinetik (t/F2a Diagramm) ist jedoch in der Regel von höherer Relevanz.

Beschreibung ETP wird gegebenenfalls bestimmt, um Aussagen über einen hyper- oder hypokoagulatorischen Status der Gerinnung eines Patienten zu machen. In der jetzigen Ausführung wird die Gerinnung der Probe durch Zusatz von einem Aktivator (TF, Calcium-Ionen, Phospholipide) in Gegenwart eines fluorogenen Thrombinsubstrats (Z-Gly-Gly-Arg-AMC) gestartet. Das gewählte Thrombinsubstrat wird nur langsam umgesetzt und bindet nicht zu stark an $>$ Thrombin, dadurch wird der Gerinnungsprozess nicht beeinträchtigt und der Substratumsatz ist proportional der Konzentration des sich bildenden Thrombins. Die Verwendung eines fluorogenen statt chromogenen Substrats erlaubt die kontinuierliche Aufzeichnung des Signals, ohne dass Fibrinogen aus der Probe entfernt werden muss, weil das Fluoreszenzsignal durch die optische Trübung durch Fibrin kaum gestört wird.

Nachteile des ETP-Tests bestehen darin, dass er durch TFund Phospholipidzusatz unempfindlich ist für (patho)physiologische Aktivatoren der Thrombingenerierung und dass der Test durch Kallikrein und durch Fibrin (Antithrombin-1) empfindlich gestört wird. Alternativ kann die endogene Thrombingenerierung mittels des RECA (,recalcified coagulation acitivity assay") bestimmt werden. Im RECA wird weder TF noch Phospholipid zugesetzt, Kallikrein bzw. nicht quervernetztes Fibrin werden durch supra-1-molares Arginin inhibiert bzw. depolymerisiert und die Thrombingenerierung wird nicht in Masse (pmol), sondern Aktivität (IE) gemessen.

\section{Literatur}

Chantarangkul V, Clerich M, Bressi C et al (2003) Thrombin generation assessed as endogenous thrombin potential in patients with hyper- or hypo-coagulability. Haematologica 88:547-553

Hemker HC, Giesen PL, Ramjee M, Wagenvoord R, Beguin S (2000) The thrombogram: monitoring thrombin generation in platelet-rich plasma. Thromb Haemost 83:589-591

Stief TW (2009) Pathological thrombin generation by the synthetic inhibitor argatroban. Hemost Lab 2:83-104 